\title{
Appearance of red mark syndrome / cold water strawberry disease in Switzerland and Austria
}

\author{
H. Schmidt-Posthaus ${ }^{1, *}$, W. Bergmann' ${ }^{2}$ R. Knüsel ${ }^{3}$, H. Heistinger ${ }^{4}$, E. Licek $^{5}$ \\ ${ }^{1}$ Centre for Fish and Wildlife Health, Institute of Animal Pathology and ${ }^{2}$ Institute of Animal Pathology, University of Bern, \\ Länggassstrasse 122, 3001 Bern, Switzerland \\ ${ }^{3}$ fishdoc GmbH, Schaubhus, 6026 Rain, Switzerland \\ ${ }^{4}$ Tierklinik Lilienfeld, Babenbergerstrasse 22, 3189 Lilienfeld, Austria \\ ${ }^{5}$ Clinic for Avian, Reptile and Fish Medicine, University of Veterinary Medicine Vienna, Veterinärplatz 1, \\ 1210 Vienna, Austria
}

\begin{abstract}
Red mark syndrome (RMS) or cold water strawberry disease (CWSD) is a non-lethal skin disease of rainbow trout Oncorhynchus mykiss that is of high economic importance in the UK. The disease is temperature-dependent, with up to $60 \%$ morbidity at water temperatures below $15^{\circ} \mathrm{C}$. Although CWSD is horizontally transmissible, the aetiology is still unknown. Here we describe the first cases of RMS on the European mainland in the alpine regions of Switzerland and Austria. In Switzerland, morbidity remained around 1\% after the first outbreak, whereas in Austria no further cases were diagnosed.
\end{abstract}

KEY WORDS: Red mark syndrome - Coldwater strawberry disease - Oncorhynchus mykiss · Austria $\cdot$ Switzerland $\cdot$ Water temperature

Resale or republication not permitted without written consent of the publisher

\section{INTRODUCTION}

Red mark syndrome (RMS), also called cold water strawberry disease (CWSD), is a recently recognised skin disease in rainbow trout Oncorhynchus mykiss. It shares similarities to strawberry disease (SD) in Europe and the United States (Fleury et al. 1985, Olson et al. 1985, Verner-Jeffreys et al. 2008). It is non-lethal, although morbidity can reach up to $60 \%$, leading to significant economic impact due to product downgrading, treatment costs, increased labour costs and increased susceptibility to secondary infections (VernerJeffreys et al. 2008). Lesions are generally seen in fish over $100 \mathrm{~g}$ at water temperatures around or below $15^{\circ} \mathrm{C}$ (Verner-Jeffreys et al. 2008). At higher temperatures, the condition seems to subside (Ferguson et al. 2006).

Clinically, RMS starts as single to multiple pale yellow to grey patches with central reddening on the flanks, dorsal and ventral surfaces. Subsequently, they become bright red, raised lesions up to several $\mathrm{cm}$ in diameter (Ferguson et al. 2006). Scale loss at the centre and epidermal ulceration can be seen. Histologically, in mild cases the epidermis is intact and the dermis including the scale pockets below the stratum compactum are infiltrated by predominantly lymphocytes. In advanced cases, scale pockets are filled with eosinophilic fluid and inflammatory cells with resorption of the scales by multinucleate giant cells or osteoclasts. In more advanced cases, the inflammatory process extends to the dermis, adipose tissue and underlying musculature (Verner-Jeffreys et al. 2008). Epicarditis, cardiomyositis, intestinal myositis, renal degeneration and focal liver necrosis have also been described (Verner-Jeffreys et al. 2008).

The cause of RMS is still unknown. An infectious agent is suspected because the disease is horizontally transmissible (Verner-Jeffreys et al. 2008). Ferguson et al. (2006) suggested Flavobacterium psychrophilum to be the aetiological agent for RMS in the UK; however, in transmission trials with previously naïve trout, this association could not be confirmed (Verner-Jeffreys et 
al. 2008). It is notable that Lloyd et al. (2008) also reported no statistical association between SD lesions and F. psychrophilum based on PCR assays, but they did find a strong association between SD lesions and a Rickettsia-like organism. Verner-Jeffreys et al. (2008) proposed that RMS is caused by 1 or more infectious agents with a long latency (>500 day-degrees).

RMS was first reported in 2003 in Scotland. RMS seemed to spread in the UK, as it was subsequently diagnosed in England and Wales (Verner-Jeffreys et al. 2008). Outbreaks outside the UK have not been reported yet. Here we describe the first likely cases of RMS on the European mainland, in 2 Swiss and 1 Austrian trout farm.

\section{CASE STUDIES AND DISCUSSION}

The 2 affected Swiss farms exclusively raise rainbow trout. Despite belonging to the same owner, they are completely separated. Farm A consists of a hatchery and a grow-out facility, which are located at 2 different sites with separate water supplies. The farm produces $250 \mathrm{t}$ of trout $\mathrm{yr}^{-1}$. The hatchery is supplied by $40 \mathrm{l} \mathrm{s}^{-1}$ spring water with a temperature of 5 to $14^{\circ} \mathrm{C}$. Eggs are supplied by brood stock kept in the grow-out facility. Additionally, each year 2 batches of eggs are imported from different farms in the European Union, but not from the UK. In the hatchery, fingerlings up to $50 \mathrm{~g}$ are reared in separate troughs and concrete raceway systems with gravel bottoms. Older animals are moved into the grow-out facility that is supplied by spring water at $250 \mathrm{l} \mathrm{s}^{-1}$ with water temperature of 4 to $14^{\circ} \mathrm{C}$. Trout are reared in separate tanks and concrete raceway systems.

Farm B produces $100 \mathrm{t}$ of rainbow trout $\mathrm{yr}^{-1}$ hatched on site in recirculation units supplied with tap water. Afterwards, fish are reared in separated flow-through troughs and tanks and then moved to independent recirculation systems. The farm is supplied by 80 to $110 \mathrm{l} \mathrm{s}^{-1}$ spring water flowing in an open channel for about $1 \mathrm{~km}$ that is inhabited by wild fish. The water is not disinfected before entering the fish farm. Water temperature ranges from 5 to $15^{\circ} \mathrm{C}$. In 2007 , rainbow trout from Farm A were once transported to Farm B.

Water parameters of both farms were checked regularly and showed no unusual variation. Rainbow trout from both farms regularly tested negative for viral haemorrhagic septicaemia (VHS), infectious haematopoietic necrosis (IHN) and infectious pancreatic necrosis (IPN) virus for the last $10 \mathrm{yr}$.

In autumn 2005, the fish farmer noticed red spots and raised red skin lesions in 5 to $50 \%$ of rainbow trout between 30 and $50 \mathrm{~g}$ in Farm A. Prevalences differed between the raceway systems. At the time, only a few older fish displayed lesions that were initially recognisable as clinical signs. Subsequently, newly affected fish were larger than $100 \mathrm{~g}$. This is in accordance with Verner-Jeffreys et al. (2008), who reported that the condition mainly affects fish over $100 \mathrm{~g}$. As water quality was the same for all age classes in Swiss Farm A, these observations point towards age susceptibility mainly in older animals. The most severe lesions in Farm A occurred at water temperatures of $6^{\circ} \mathrm{C}$ or below. In Farm B, similar skin lesions were seen only occasionally in fish larger than $300 \mathrm{~g}$.

The Austrian farm produces about $2.5 \mathrm{t} \mathrm{yr}^{-1}$ of rainbow trout, brown trout and brook trout, which are hatched on site. The different salmonid species are kept in separate tanks. The farm is supplied with spring water that flows at $261 \mathrm{~s}^{-1}$ separately to concrete raceway systems, a hatchery, a pond and a basin. The median water temperature is $11^{\circ} \mathrm{C}$ and never exceeds $14^{\circ} \mathrm{C}$. The farm is free of the notifiable viral diseases VHS and IHN. Clinical signs as those described for the Swiss farms were noted in autumn 2007 and affected only rainbow trout larger than $100 \mathrm{~g}$. Increased mortalities were not reported.

For diagnostic purposes, trout from all 3 farms were sacrificed and necropsied. At necropsy, animals from Switzerland and Austria showed similar lesions. Affected fish had single to multiple white-gray to red, slightly raised alterations up to $3 \mathrm{~cm}$ in diameter on the ventral surface, the flank and the tail (Fig. 1). Fresh mounts of skin and gill samples revealed no external parasites. Bacteriological examination of skin, liver, spleen and kidney using blood agar plates (Bio Merieux), bromothymol blue-lactose-agar plates and Cytophaga agar plates for detection of Flavobacterium spp. revealed no pathogenic bacteria. Routine histopathological examination of formalin-fixed skin sam-

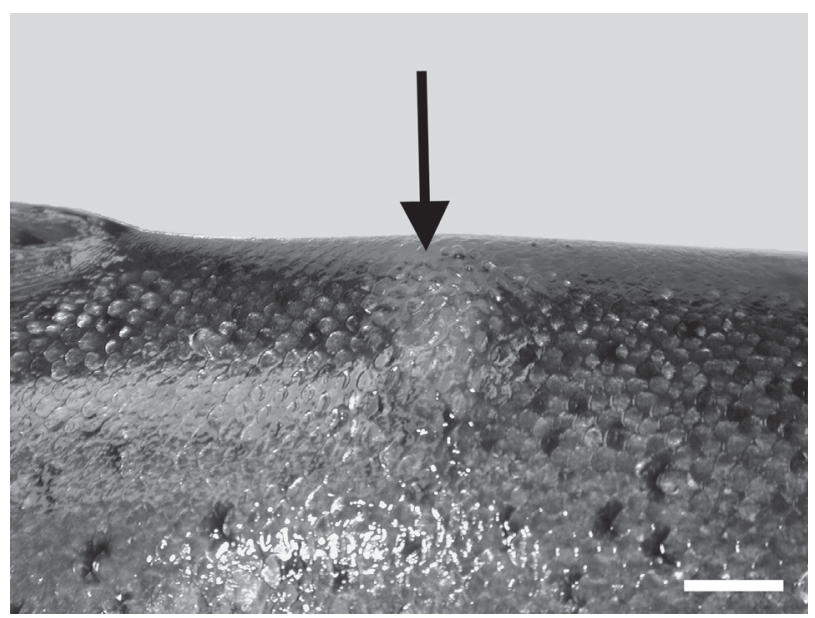

Fig. 1. Oncorhynchus mykiss. Macroscopic view of a red, slightly raised alteration (arrow) on the flank of a rainbow trout from Swiss Farm A. Scale bar $=1 \mathrm{~cm}$ 
ples was performed. In a small number of investigated animals from Swiss Farm A, the dermis including the scale pockets were infiltrated by moderate amounts of macrophages, lymphocytes and neutrophilic granular cells. The scale pockets were extended due to oedema and accumulation of necrotic debris, haemorrhage, and the aforementioned inflammatory cells (Fig. 2a). In most cases, however, more advanced lesions were observed. The dermis was diffusely infiltrated by large numbers of macrophages, lymphocytes and plasma cells. The scale pockets were moderately dilated and infiltrated with moderate numbers of macrophages, lymphocytes and multinucleated giant cells (Fig. 2b).

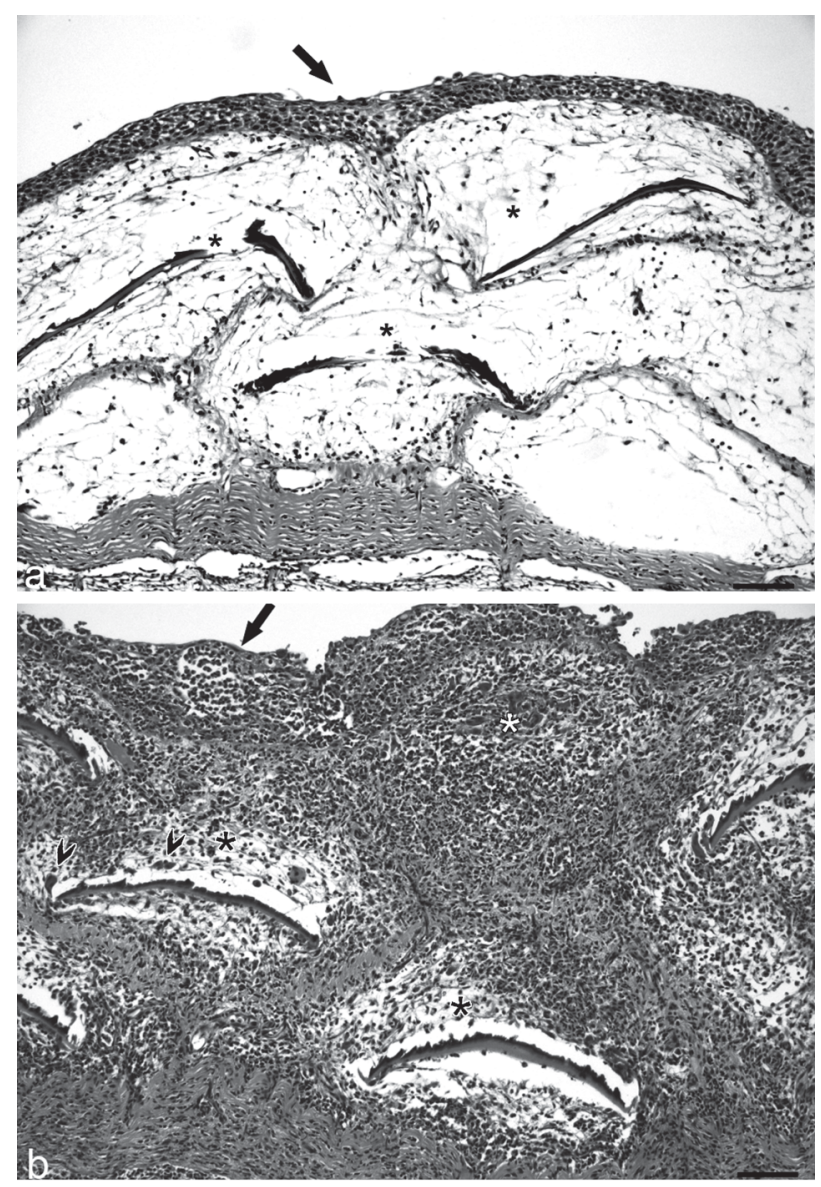

Fig. 2. Oncorhynchus mykiss. (a) Histological section of skin lesions seen in a few rainbow trout from Swiss Farm A, showing dermis including scale pockets (stars) distended by oedema and few neutrophilic granular cells, lymphocytes and macrophages; epidermis is still intact (arrow). (b) More advanced case, showing dermis including scale pockets (black stars) severely distended due to infiltration by large numbers of macrophages, lymphocytes and plasma cells, multinucleated giant cells along scales (arrowheads), scale completely absent, scale pocket filled with inflammatory cells including multinucleated giant cells (white star), overlying epidermis degenerated, exocytosis of mainly lymphocytes (arrow). Scale bars $=100 \mu \mathrm{m}$, stain = haematoxylin and eosin
Multiple scales were degraded or completely absent. Multifocally the inflammatory cells infiltrated into the superficial muscular layers. There was exocytosis of mainly lymphocytes in the overlying epidermis, which showed multifocal erosion and loss. A presumptive diagnosis of RMS was made, as the clinical and morphological characteristics of the skin lesions and the environmental conditions corresponded to those previously described as being characteristic for this syndrome by Ferguson et al. (2006) and Verner-Jeffreys et al. (2008). On the Swiss farms, some animals recovered spontaneously. In Farm A, trout were additionally treated with oxytetracycline. After the first incident, fingerlings in both Swiss farms were preventatively treated with sodium percarbonate on a regular basis. Nevertheless, approximately $1 \%$ of fish larger than $100 \mathrm{~g}$ still developed skin lesions thereafter.

On the Austrian farm, animals were treated with oxytetracycline and vitamin A-supplemented food. All affected rainbow trout recovered completely, and no more outbreaks were reported since the original outbreak.

RMS is thought to be responsive to antibiotic treatment (Ferguson et al. 2006, Verner-Jeffreys et al. 2008), although a scientific proof for the effectiveness of this treatment has not been published to date. Whether the clinical condition responded to oxytetracycline treatment in our cases cannot be answered conclusively. Another possible reason for the reduced prevalence in Farm A is the treatment of fingerlings with sodium percarbonate. Because RMS is possibly caused by one or several, as yet unidentified, infectious agents (Verner-Jeffreys et al. 2008), prophylactic disinfection might prevent or at least reduce infections of fingerlings. Nevertheless, identification of the causative agent is required for a scientific evaluation of the effectiveness of different treatments for RMS.

Similar to previous studies, we were not able to identify a particular infectious agent as the cause of the clinical RMS in our cases. In addition to this, the source of infection remains unclear. Reports of RMS were previously restricted to the UK. Although Fleury et al. (1985) already described similar skin lesions in rainbow trout in France in 1985, the clinical and histopathological data were very similar to those of SD as described by Olson et al. (1985), where no correlation was found between the temperature of the water and the appearance of the skin lesions as seen in RMS. Also according to Ferguson et al. (2006) and VernerJeffreys et al. (2008), this disease is similar but not identical to RMS. However, because further reports in Europe are missing, the question of whether Fleury et al. (1985) described cases of SD or RMS cannot be answered conclusively. Verner-Jeffreys et al. (2008) reported introduction of RMS in a naïve rainbow trout 
farm by import of infected stock animals. In the Swiss farms, transport of fish from Farm A to Farm B was reported, making a transmission of infectious agents between these 2 farms possible. However, both the Austrian and Swiss farmers reported no introduction of new fish from outside sources into their farms. Swiss Farm A regularly imported eggs. Although reports suggesting eggs as a source for RMS are lacking, introduction of RMS into affected farms through eggs cannot be completely excluded.

Thus far, RMS has only been reported in rainbow trout (Ferguson et al. 2006, Verner-Jeffreys et al. 2008). Corresponding to this, no brown or brook trout showed any RMS lesions on the Austrian farm during the entire period. This raises the question of whether certain salmonid species other than rainbow trout could be the reservoir of an infectious agent, causing RMS in susceptible species like rainbow trout.

All 3 affected farms are located in the alpine regions where water temperatures would favour diseases such as RMS, which is known to occur only at water temperatures below $15^{\circ} \mathrm{C}$ (Ferguson et al. 2006, Verner-Jeffreys et al. 2008). It is unclear whether fish at higher water temperatures can serve as reservoirs for RMS, which then becomes clinically apparent only at low water temperatures. If this is the case, a wide distribution of a potential infectious agent cannot be excluded.

Presently, the disease seems to have less economic importance on the European mainland compared to the UK. However, further spread of the disease could

Editorial responsibility: Bernd Sures, Essen, Germany cause increasing economic losses, especially among farms located in cold water areas, such as the alpine region. The potential further spread of the disease should be closely monitored through diagnosis of the typical clinical and pathological features of RMS. Our report underlines that identification of the suspected infectious agent causing RMS is urgently needed. Studies to clarify the routes of infection and spread of the disease as well as preventive measures will largely rely on sensitive and specific methods to detect the disease-causing pathogen.

\section{LITERATURE CITED}

Ferguson HW, Girons A, Rizgalla G, LaPatra S and others (2006) Strawberry disease in rainbow trout in Scotland: pathology and association with Flavobacterium psychrophilum. Vet Rec 158:630-632

Fleury HJA, Vuillaume A, Sochon E (1985) Isolation of an adeno-like virus from two cases of strawberry disease in rainbow trout. Ann Inst Pasteur 136:223-228

- Lloyd SJ, LaPatra SE, Snekvik KR, St-Hilaire S, Cain KD, Call DR (2008) Strawberry disease lesions in rainbow trout from southern Idaho are associated with DNA from a Rickettsia-like organism. Dis Aquat Org 82:111-118

> Olson DP, Beleau MH, Busch RA, Roberts S, Krieger RI (1985) Strawberry disease in rainbow trout, Salmo gairdneri Richardson. J Fish Dis 8:103-111

> Verner-Jeffreys DW, Pond MJ, Peeler EJ, Rimmer GSE and others (2008) Emergence of cold water strawberry disease of rainbow trout Oncorynchus mykiss in England and Wales: outbreak investigations and transmission studies. Dis Aquat Org 79:207-218

Submitted: April 16, 2009; Accepted: September 22, 2009 Proofs received from author(s): December 14, 2009 